\title{
Derechos Humanos y Fuerza Armada
}

Parte esencial de los Acuerdos de Paz fue el compromiso asumido por los firmantes para definir un nuevo marco doctrinal y jurídico dentro del cual se desarrollasen las actividades de la Fuerza Armada. Con ello se pretendía dejar atrás el perfil que hasta entonces la había caracterizado: hermética, autónoma con respecto a la sociedad civil, al margen de las obligaciones impuestas por el Estado de Derecho y los Derechos Humanos.

Pese a que, luego de concluida la guerra, se dieron hechos que pusieron en entredicho este afán renovador de las filas y el espíritu castrenses (por ejemplo, la poca disposición de las autoridades gubernamentales y militares para darles de baja a aquellos elementos acusados de violaciones a los Derechos Humanos), todo hacía pensar que, al menos en las nuevas "tandas" de oficiales, la doctrina militar de postguerra empezaba a cobrar efecto. Que la vieja guardia de los militares, desde siempre reacia al cambio y a la obediencia al poder civil, no pusiera ningún empeño en la tarea impuesta por las nuevas circunstancias de la sociedad salvadoreña, no permitía suponer que, en su conjunto, la Fuerza Armada no estuviera dando pasos importantes hacia su modernización y reestructuración.

Sin embargo, el 14 de este mes, salió a la luz pública un incidente que ha vuelto a poner sobre el tapete de la discusión el delicado tema de la relación entre el ejército y los Derechos Humanos. Según fue dado a conocer por los medios de comunicación, 66 cadetes de la Escuela Militar "General Gerardo Barrios", en el transcurso de una práctica de patrullaje rutinaria, habrían sido expuestos por su instructor, como forma de castigo, a los efectos directos de los químicos contenidos en una bomba de gas lacrimógeno; como resultado, los cadetes sufrieron quemaduras de primero y segundo grados en sus rostros.

Ante el hecho, el Director de la Escuela Militar, Coronel David Munguía Payés, afirmó que ya se habían iniciado las investigaciones en tomo al caso y que, mientras se llegaba a alguna conclusión, el responsable de las lesiones se encontraba arrestado y había sido suspendido temporalmente de su cargo. Por su parte, el Presidente Calderón Sol afirmaba haber ordenado una investigación profunda sobre el supuesto castigo, con el fin de "destituir, dar de baja, o pasar [al instructor] a los tribunales, si hay responsabilidad penal".

En general, las declaraciones de los funcionarios, ya fueran civiles o militares, se enfocaron en señalar que el incidente había sido algo excepcional, negándose con ello que la brutalidad o la crueldad continuaran siendo, como antaño, elementos cotidianos en el proceso de instrucción militar. El inmediato sometimiento del oficial responsable del"incidente a los procesos de justicia militar, según las declaraciones oficiales, era muestra de que no se tolerarían episodios semejantes. Como corolario del incidente, el 1 de noviembre el ministro de Defensa, general Jaime Guzmán Morales, anunciaba que el capitán Cristóbal Flores, instructor responsable de las quemaduras de los cadetes, había recibido la orden definitiva de abandonar la institución por "graves faltas cometidas durante el servicio".

Con el fin de analizar este hecho es útil recordar algunos de los elementos de la nueva doctrina militar que en teoría imperan en el interior de las filas castrenses y que definen la relación del ejército con la sociedad. 
Disciplina, honor y espíritu de cuerpo en el ejército

Con la llegada de la paz, la Fuerza Armada y ONUSAL establecieron un ideario al que deberían adecuarse las actividades militares - tanto en el interior como en el exterior del cuerpo ( $\mathrm{C} r f$., $\mathrm{Mi}$ nisterio de la Defensa Nacional y ONUSAL, Doctrina Militar y Relaciones ejército/sociedad). En este ideario se contemplaron tres conceptos claves para regir, una acción militar, acorde con la incipiente sociedad democrática salvadoreña:

(a) Disciplina. Entendiendo por ella no una "obediencia debida", sino más bien una "disciplina estricta". Es decir, el concepto de una obediencia ciega, en la que el subalterno es sólo el brazo ejecutor - libre de responsabilidad individual- de las órdenes de su superior, incluso estando éstas fuera de la legalidad, da paso a una disciplina en la que el subordinado puede y debe abstenerse de cumplir una orden cuando su ejecución conlleva cualquier tipo de delito o acción ilegal. En este tipo de disciplina, tanto el que ordena como el que ejecuta serian igualmente responsables de la ilegalidad de las acciones cometidas.

(b) Honor. Según la doctrina militar vigente desde los Acuerdos de Paz, el honor militar se define a partir de la posesión y defensa del conjunto de valores establecidos por la Constitución y los Derechos Humanos. En este sentido, hacer valer el honor militar significaría, por un lado, velar porque estos valores orienten la acción de cada uno de los miembros del ejército y, por el otro, facilitar la tarea de cualquier organización que pretenda verificar el respeto de los mismos en el interior de las filas castrenses. En consecuencia, la labor de investigación de una institución como la Procuraduría para la Defensa de los Derechos Humanos (PDDH) no atentaría contra el honor militar, sino que, por el contrario, contribuiría a que éste se robusteciera.

(c) Espíritu de cuerpo. Siendo por sus características intrínsecas un grupo social con un "sentimiento corporativo", el ejército se percibe a sí mismo como diferente al resto de la sociedad y crea fuertes lazos de cohesión interna entre sus miembros. Teniendo en cuenta esto, habrían dos modelos -en sí mismos contrapuestos- de entender este corporativismo.

En el primer modelo, el ejército se concibe como un colectivo cerrado que defiende intereses compartidos a través de una unidad que está por encima de la moral y el cuerpo jurídico de la sociedad. En este marco, la especificidad propia del cuerpo radicaría en su extrañamiento radical de las esferas de valores que imperan en el resto de la estructura social, contemplándose cualquier señalamiento o crítica proveniente de afuera como una amenaza o ataque a la integridad y seguridad de la corporación. Por ello, la protección incondicional a uno de los miembros del ejército acusado de cometer actos ilegales sería equivalente a la defensa del colectivo en su conjunto. Cualquier falta a la normativa que impera en el resto de la sociedad - por muy grave que esta sea- quedaría disculpada por la necesidad de hacer valer la unidad y los intereses del cuerpo.

Al contrario de lo anterior, el espíritu de cuerpo de la nueva doctrina militar parte del supuesto de que la corporación militar está compuesta por individuos con un alto nivel ético y con un concepto de honor similar al ya definido. Los cuales, además, son conscientes de que la pertenencia al cuerpo no está asegurada definitivamente. En consecuencia, este modelo de corporativismo implica un alto nivel de exigencia ética, en el cual cualquier violación a los Derechos Humanos constituye una violación intolerable del honor militar. Por lo tanto, cualquier individuo que cometa delitos, sean del género que sean, no será encubierto o protegido, sino juzgado, sentenciado y separado de la institución.

Como es obvio, cada uno de esto conceptos regula un ámbito en particular de la vida castrense y en su debida interrelación definen el carácter global de una nueva Fuerza Armada. Por su lado, el concepto de disciplina estricta norma las relaciones entre los miembros del cuerpo y establece un patrón de conducta que permite discernir el grado de responsabilidad correspondiente a cada uno de los sujetos que se vean implicados en cualquier acción. Complementariamente, el honor militar, tal como se ha descrito, traza el marco de valores y deberes que orientarán la acción de los miembros del ejército; traza, pues, los límites dentro de los cuales se cristaliza una disciplina responsable. Finalmente, el nuevo espíritu de cuerpo cohesiona los dos anteriores conceptos, sienta la actitud que adoptará la corporación para con sus miembros y define la relación entre el ejército y la sociedad civil. Así pues, el nuevo cariz de la Fuerza Armada queda estrechamente vinculado a la 
adecuación estricta de la institución a cada uno de estos tres elementos inseparables.

Con lo dicho hasta aquí, es obvio que el significado del incidente supera al que le han querido asignar las autoridades gubernamentales y castrenses. Ciertamente, la brutalidad mostrada por el instructor para con sus subalternos se constituye en una afrenta al honor militar, y ello es digno de atención y castigo. Pero esto, más que motivar una discusión sobre la acción de un sujeto en particular, debería servir para problematizar sobre el tipo indeseado de disciplina que opera en una instrucción en la que los cadetes o reclutas se someten mansamente a circunstancias denigrantes y en las que se pone deliberadamente en peligro su integridad física. En este sentido, la falta al honor militar no sólo es patrimonio de un oficial ofuscado a la hora de aleccionar a sus subordiados, sino también de los alumnos que obedecen a sus designios y de la institución que todavía no relaciona en la práctica la modalidad de disciplina necesaria para respaldar el código de honor esperado.

Obviamente, no es posible medir los métodos de aprendizaje y disciplina del ejército desde lo que cabría esperar en instituciones civiles. Parte esencial de la vida castrense es el sacrificio, el estoicismo ante situaciones adversas, la instrucción espartana. La formación militar busca, pues, formar individuos recios, duros, pero ello no permite afirmar, al menos en un modelo de ejército como el ya definido, que los métodos empleados para forjar sujetos de tal talante supongan la disolución absoluta de sus derechos. Este tipo de formación, en la que la humanidad de los que a ella se someten se transforma en mera animalidad, tiene un resultado previsible - comprobado en las múltiples guerras en las que se ha embarcado el hombre-: la producción de máquinas homicidas privadas de conciencia y del mínimo respeto a la vida humana. Este es el pasado que buscaría superarse con la nueva doctrina militar. En ella, la formación de los reclutas en áreas humanísticas, enfocadas al conocimiento y respeto de los Derechos Humanos es parte imprescindible de la vida militar.

Sin embargo, está formación humanística debe de estar respaldada por códigos de conducta orientados por el imperativo de hacerla valer en la práctica. Siendo esto último la razón de ser de la disciplina estricta y el código de honor. Ahora bien, el castigo impuesto a los 66 cadetes rompe con ambos elementos y pone en duda la solidez de la formación humanística recibida, tanto de los cadetes como del instructor. Evidentemente, la acción del instructor fue desproporcionada y estuvo al margen de los métodos disciplinarios que, en teoría, rigen la vida militar. Empero, lo que debe de llamar la atención es la condición subjetiva para que un abuso de este tipo tuviera lugar: un grupo de alumnos incapaces de negarse a obedecer una orden que atentaba contra su propia integridad y contra algunos de los valores fundamentales del código de honor vigente.

Es decir, el incidente ha mostrado lo poco que ha cambiado el ejército en su interior: puede ser que la conducta del instructor sea una excepción, que los otros oficiales encargados de formar a los reclutas no se manejen de la misma manera, pero si existe la disposición de los subalternos a obedecer sin reparos una orden, aun cuando ésta vaya en contra del supuesto espíritu humanista del cuerpo, continúa presente la posibilidad de que la acción del ejército pueda desbordarse en contra de la sociedad sin mayor problema. Los que han pretendido disminuir la gravedad del incidente parecen olvidar que el respeto de los Derechos Humanos en el interior del ejército es la condición sine qua non del respeto a los derechos de los ciudadanos.

Empero, esta falta de coherencia con los conceptos bajo los cuales debería de operar el ejército en su interior no se ha presentado sola. El 
que los delegados de la PDDH nombrados para investigar el caso hayan visto entorpecida su labor por la negativa de las autoridades militares a conceder entrevistas y dar oportunidad a que los cadetes declararan (ver El Diario de Hoy, 15 de octubre de 1997, p. 7), es signo de que el mayor de los males de la relación entre el ejército y la sociedad no ha sido superado: el ejército aún se mantiene hermético ante el lente oscultador de la sociedad civil. A todas luces, la sanción militar al instructor acusado de violar los Derechos Humanos de sus cadetes fue necesaria, pero no es suficiente. Evitar o entorpecer la labor de establecer responsabilidades civiles es, inequívocamente, dar continuidad a la impunidad de la que gozaron los militares tradicionalmente. Sólo en la medida en que el incidente trascendiera la esfera militar y el responsable fuera sometido a los procedimientos judiciales civiles podría afirmarse que, por una vez en la historia reciente, el poder castrense no es una bestia incontrolable que se mantiene totalmente al margen de la lógica de la democracia y los Derechos Humanos.

Marcel Vargas Escolero 